\title{
Research on Permanent Income Hypothesis and Steady Development of Real Estate Market in China
}

\author{
Ying Zhang, a , Wei Yang ${ }^{1, b}$ \\ ${ }^{1}$ Xi’an Fanyi University, Xi’an, 710105, China
}

Keywords: Permanent income, Real estate, Steady

\begin{abstract}
The real estate industry is one of the pillar industries in China's national economy. Because of the particularity of its resources, every fluctuation will cause the whole society to pay close attention to it. Especially, the residential housing market has become a necessary condition for the stability of the national economy. Based on the permanent income of residents, the interactional relationship between income fluctuation as well as consumption selection and the real estate price to propose relevant suggestions and measures of China's current resident income policies and the real estate market policies.
\end{abstract}

\section{Introduction}

The real estate industry has experienced rapid growth after more than ten years, in the macro-control under the government's growth has stabilized, but in 2016 the north of the Guangzhou Shenzhen as the representative of the first-tier cities and many second-tier city housing prices rose rapidly once again the real estate industry will be pushed to the public governance in the teeth of the storm on the current issues of China's economic development. With the purchase of major cities at the end of the purchase order and bank lending tightened, the real estate industry once again attributed to the overall calm. The prosperity of the industry, so that the government and the public has become the future development of China and stable economic development is highly related to the consensus of the real estate industry, but the future direction of development of the real estate industry is whirling Chinese. Because the real estate has a dual property, investment and consumption in our level of demand from the perspective of wealth in real estate, as part of the residents' income of residents, lasting impact of income volatility on the real estate market in China.

\section{Theoretical Synthesis}

The 1929 global economic crisis makes the economics research on the national economy towards consumption from the realm of production, in 1936 Keynes (Keynes) proposed the hypothesis of absolute income marks was formally incorporated into the theory of consumption economics research category, which has caused scholars in the consumption theory more deeply, and have achieved fruitful results. Among them, there are representative: Modigliani (Modigliani, 1954) life cycle hypothesis, Freedman (Friedman, 1957) persistent income hypothesis. Holzer (Hall, 1978) put forward the hypothesis of random walk based on the introduction of rational expectation into life cycle and persistent income hypothesis. To 1980s, in the (Flavin, 1981), Campbell and Deaton (Campbell and Deaton, 1989) as the representative, are put forward and excessive sensitivity over smoothing, questioning and correction to the Holzer hypothesis, and based on the derived liquidity constraints hypothesis, precautionary saving hypothesis, loss aversion hypothesis, greatly rich of consumption theory research.

The relationship between consumption and real estate, the new classical theory that consumption is a function of income and wealth, each Friedman that consumers consumption depends on expected income, and as the labor income and capital gains (including real estate capital gains) of discounted value. The life cycle hypothesis Modigliani pointed out that consumers in the early stage of its life in 
the expected future income, in the middle period of the accumulation of wealth and debt repayment, elderly consumption will be the accumulation of wealth, so that consumers will be allocated to the average wealth of the expected remaining life, achieve the life to smooth consumption. Housing, as a major asset component of the family, will have a significant impact on consumption if its price exceeds the expected sustainability of the consumer.

In the research on the relationship between the stock and real estate stocks and real estate, although all belong to the forms of wealth, and the impact on consumption, but because of the difference method of asset attributes, people pay attention to these differences will have different effects on consumption. Therefore, more and more scholars have studied the real estate market and the stock market separately, and further analyzed the relationship between them and consumption. In recent years the representative research results are: Quigley \& Shiller (2005) in the study of the relationship between housing wealth and financial wealth and consumption between after the analysis of real estate price fluctuation on consumption significantly, while price fluctuations in the stock market impact on consumption weak.

Based on the above theory, the author will combine the permanent income theory and life cycle theory, combined with the macro data and micro data, analyzing the consumer prices, and the stock market, the relationship between the savings using the system GMM method.

\section{Variable Description and Data Process}

In this paper, the panel data of 30 provinces in China during 2008-2015 years and 8 years are adopted. The main variables include household consumption (c), property income (wr), savings (s) and disposable income (pi)

$$
\begin{gathered}
c=w r+p i \\
w r=f c+l c
\end{gathered}
$$

Property income (wr) is mainly made up of real estate income (ec) and financial asset income (fc), while s, as part of the family wealth, becomes a potential household consumption and is believed to happen in the future. pi is the disposable income of the family.

Therefore, household consumption can be written as:

$$
\mathrm{c}=\mathrm{fc}+\mathrm{ec}+\mathrm{pi}+\mathrm{s}
$$

According to Campbell's hypothesis of sustained income, the short-run consumption model and the long-term consumption model can be expressed as:

$$
\begin{aligned}
& c_{k}=\mathrm{a}_{0}+\alpha_{1} f c_{k}+\alpha_{2} f c_{\mathrm{k}-1}+\beta_{1} e c_{k}+\beta_{2} e c_{\mathrm{k}-1}+\gamma_{1} \mathrm{pi}+\gamma_{2} p i_{\mathrm{k}-1}+u_{k} \\
& c_{k}=\mathrm{a}_{0}+\sum_{i=1} \alpha_{i} f c_{k}+\sum_{i=1} \beta_{i} e c_{k}+\sum_{i=1} \gamma_{i} p i_{k}+u_{k}
\end{aligned}
$$

Consumption is influenced by income as well as by savings, which can be obtained by bringing savings variables into a sustainable income model:

$$
\begin{gathered}
c_{k}=\mathrm{a}_{0}+\alpha_{1} f c_{k}+\alpha_{2} f c_{\mathrm{k}-1}+\beta_{1} e c_{k}+\beta_{2} e c_{\mathrm{k}-1}+\gamma_{1} \mathrm{pi}+\gamma_{2} p i_{\mathrm{k}-1}+\lambda \mathrm{s}_{k}+u_{k} \\
c_{k}=\mathrm{a}_{0}+\sum_{i=1} \alpha_{i} f c_{k}+\sum_{i=1} \beta_{i} e c_{k}+\sum_{i=1} \gamma_{i} p i_{k}+\lambda s_{k}+u_{k}
\end{gathered}
$$

$\alpha, \beta, \gamma$ are time coefficients, that is, the closer the time is, the greater the coefficient of time is, and the less the other is. $\mathrm{i}=1,2, \ldots \mathrm{n} . \mathrm{k}=\mathrm{t}, \mathrm{t}-1 . . \mathrm{t}-\mathrm{m}$; $\mathrm{u}$. The random error term is used to represent the influence of the random perturbation factor on the result.

\section{Empirical Analysis}

In panel OLS method, table 1, second and third columns respectively for fixed effects (FE) and random effects (RE) estimation results in Hausman test and found the model to reject the null hypothesis at the $1 \%$ level, so the fixed effect model is the ideal choice.

According to the fixed effect analysis, the fluctuation of house price has positive influence on consumption, and is significant at the $1 \%$ level. The income of financial assets has positive influence on consumption, but the influence is weaker. Visible, although changes in income will not expected 
to cause changes in consumption, but the capital market is weak and the weak ability to create wealth, to make our financial assets income on consumption ability is not obvious. Personal disposable income has a positive impact on consumption, and the impact is very significant, and the savings factor is negative, which proves that savings have an inhibitory effect on consumption.

Table 1. Estimated results of OLS reminded by2SLS

\begin{tabular}{|c|c|c|c|c|}
\hline \multirow[b]{2}{*}{$\mathrm{a}$} & \multicolumn{2}{|c|}{ OLS } & \multicolumn{2}{|l|}{ IV } \\
\hline & $\begin{array}{c}0.73645 * * * \\
(0.000)\end{array}$ & $\begin{array}{c}0.94640 * * * \\
(0.000)\end{array}$ & $\begin{array}{c}0.80997 * * * \\
(0.000)\end{array}$ & $\begin{array}{c}0.8577 * * * \\
(0.000)\end{array}$ \\
\hline lnec & $\begin{array}{c}0.01632 * \\
(0.832)\end{array}$ & $\begin{array}{r}0.04166 * \\
(0.526)\end{array}$ & $\begin{array}{c}0.02942 * \\
(0.580)\end{array}$ & $\begin{array}{c}0.042 * \\
(0.590)\end{array}$ \\
\hline $\operatorname{lnfc}$ & $0.00818^{* * *}$ & $0.006756 * * *$ & $0.00132^{* *}$ & $0.00155^{*}$ \\
\hline lnpi & $\begin{array}{l}(0.004) \\
0\end{array}$ & $\begin{array}{l}(0.008) \\
0954524\end{array}$ & $\begin{array}{l}(0.501) \\
0\end{array}$ & $\begin{array}{l}(0.553) \\
0\end{array}$ \\
\hline $\operatorname{lns}$ & $\begin{array}{c}(0.000) \\
-0.13672 * * \\
(0.467)\end{array}$ & $\begin{array}{c}(0.000) \\
-0.05650 * \\
(0.686)\end{array}$ & $\begin{array}{c}(0.007) \\
-0.23239 * * * \\
(0.004)\end{array}$ & $\begin{array}{c}(0.026) \\
-0.2429 * * * \\
(0.0033)\end{array}$ \\
\hline $\begin{array}{c}\text { Panel setting } \\
\text { F test }\end{array}$ & $\begin{array}{c}19.9 \\
{[0.0021]}\end{array}$ & & & \\
\hline $\begin{array}{c}\text { Hausman } \\
\text { test }\end{array}$ & & $\begin{array}{c}26.90 \\
{[0.0000]}\end{array}$ & $\begin{array}{c}5.07 \\
{[0.0055]}\end{array}$ & $\begin{array}{c}3.97 \\
{[0.0438]}\end{array}$ \\
\hline $\begin{array}{l}\text { Durbin-Watson } \\
\text { endogenous test }\end{array}$ & & & $\begin{array}{l}1.07828 \\
{[0.001]}\end{array}$ & $\begin{array}{c}0.77828 \\
{[0.000]}\end{array}$ \\
\hline Sargan test & & & $\begin{array}{l}29.5911 \\
{[0.572]}\end{array}$ & $\begin{array}{c}42.97 \\
{[0.3650]}\end{array}$ \\
\hline
\end{tabular}

Note: Within the standard deviation coefficient of variance, $\mathrm{P}$ test statistics []; the $* * * * * *$ and $*$, respectively $1 \%, 5 \%$ and $10 \%$ significant level; the panel set the null hypothesis $\mathrm{F}$ test is the individual effect is not significant, if there is a rejection of the null hypothesis of random effects; the null hypothesis of the Hausman test is no systematic difference between the estimated coefficient of Fe and re; the Durbin-watson test of the null hypothesis is the endogenous variable is exogenous, if that is to reject the null hypothesis that the variables are endogenous; the null hypothesis Sargan test is instrumental variables over recognition, if accept the null hypothesis is instrumental variables reasonable.

However, since real estate is both consumer goods and capital gains, this will lead to the endogeneity of real estate consumption. Moreover, the relationship between savings and consumption will also lead to endogenous problems. To reduce the deviation of endogeneity to model analysis, we take the instrumental variable (IV) estimation method. According to the requirement of instrumental variable setting, since the lag period of the independent variable is not related to the residual term as the instrumental variable and is related to the endogenous variables, we choose $s(-1)$ and EC (-1) as the instrumental variables. To test the effectiveness of instrumental variables, using the Sargan test of 0.572 , that is not at the level of $10 \%$ to the instrumental variables are original hypothesis over identification, proof of instrumental variables are exogenous variables, that tool is reasonable.

From the instrumental variable 2SLS analysis, the estimate coefficient of housing prices has risen to 0.0294 , and the change has been $74 \%$, indicating that the endogeneity problem seriously underestimated the impact of housing prices on consumption. The estimated coefficient of saving up to 0.2324 , changes in $76 \%$, and the coefficient becomes negative, because the savings is a decreasing function of consumption, visible long-term savings have inhibitory effect on consumption in the short 
term, but it can greatly stimulate the long-term consumption, this is also in recent years in China. The proportion of consumption increased gradually confirmed in GDP.

To ensure the reliability of the analysis results, we test the robustness of the model further. In this case, we use the maximum likelihood estimation, the hysteresis analysis and the dynamic panel estimation to test the model.

Table 2. Results of robust test

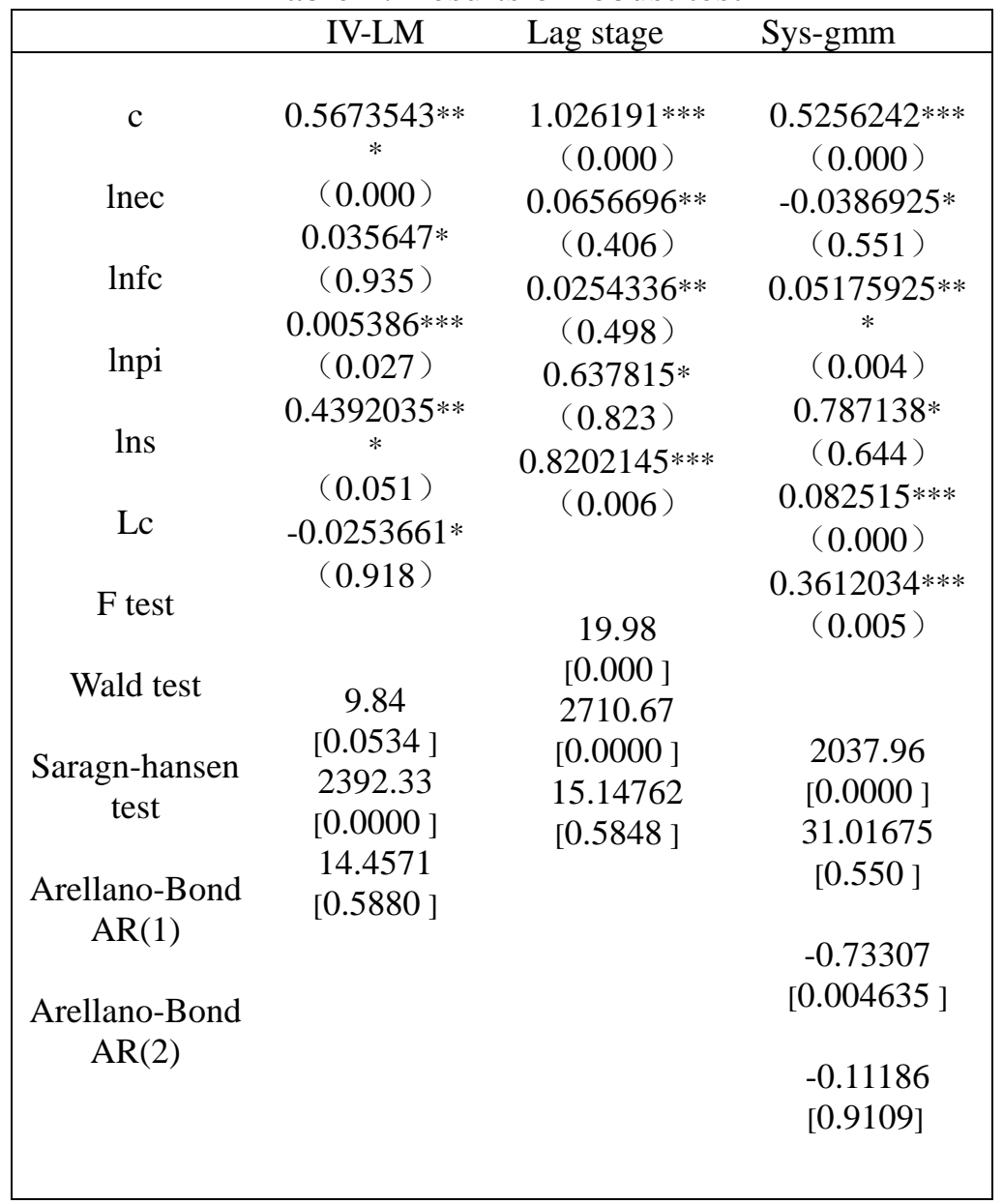

Note: For heteroscedasticity standard coefficient difference, $\mathrm{P}$ test statistics []; the $* * * * *$ and $*$, respectively $1 \%, 5 \%$ and $10 \%$ significant level; the Wald test the null hypothesis of instrumental variables is weak recognition, if to reject the null hypothesis that instrumental variables is reasonable; the null hypothesis of the Saragn-hansen test is "instrumental variables for excessive recognition", if accept the null hypothesis that instrumental variables is reasonable; Arellano-Bond AR (1) and AR (2) to test the null hypothesis does not exist first-order autocorrelation and two order autocorrelation.

From the table 2 test results, the first column maximum likelihood estimation results are similar to the 2SLS estimation results, which shows that the model estimation results are not affected by the weak instrumental variables, and the analysis results are robust. See from the dynamic panel estimation results, financial assets income, disposable income and savings has a significant effect on consumption, while the price coefficient from negative to positive, indicating that the real estate price fluctuation has inhibitory effect on household consumption in China, this is because the words of long-term residence, housing prices rose only compensation the rental costs, other costs and prices rise with the rise in the redistribution effect of inhibiting the growth of consumption.

\section{Conclusion and Implications}

We can see from the provincial panel data analysis of China's residents' long-term income:

(1) The main factors affecting the current and future consumption of our residents are disposable income. As the contribution rate of consumption in our country becomes more and more high, the mode of economic growth in China is changing from investment type to consumption type in GDP. 
Therefore, to continue to deepen fiscal and tax reform as the core of the package of the income distribution system reform, the continued implementation of the national income doubling plan to improve the national disposable income, improve the ability of the consumer has a positive role in promoting.

(2) The financial assets income of Chinese residents' consumption in the short term effect is weak, but the long-term effect is prominent gradually, indicating that the current financial capital market development on the income growth promoting effect is limited, in addition to their own lack of capital market, financial assets transaction size accounted for a low proportion of GDP residents, capital participation is not enough to make financial assets effect of income on consumption is not obvious. In the long run, the continuous improvement of the capital and financial markets, to attract social capital into the country, to enhance the level of national wealth, to promote consumption. Therefore, the government needs to continue to deepen the reform of the capital and financial markets, optimize the allocation of financial resources, improve the efficiency of China's capital and financial markets, strengthen the vitality of the capital and financial markets, and improve the financial income of residents.

(3) The short-term savings on consumption in the inhibitory effect of the current income in part did not translate into consumption, from the long-term savings of wealth storage characteristics, is the guarantee to enhance the potential and future consumption capacity of the residents, and will eventually become the reality of consumption, and early savings is stronger, the stronger the ability of the future consumption. But in recent years China's consumption growth is one of the main reason for the strong. Therefore, the government should guide consumption reasonably, increase the transformation efficiency of savings to consumption, and provide market support for the smooth progress of China's supply side reform.

(4) The real estate prices in the short term can rapidly increase the wealth of residents, wealth effect in the short term will stimulate the consumption level of residents rising. However, in the long-term results, real estate income rising just as residents higher rent cost compensation, the income does not improve the income level of residents' real people, the redistribution effect caused by high prices will further weaken the ability of the consumer to form the inhibitory effect on consumption. Therefore, the government should optimize the supply structure of real estate market, speed up the real estate tax reform to curb the rapid rise in prices, guide the rational flow of funds in the market in the real estate market, and promote the healthy development of the real estate market stability.

\section{Acknowledgements}

The research is the periodical result of "Science Planning Project of Education Department of Shaanxi Province in 2016" named "Research on Behaviors Selection and Marginalization Consequences of Low-income Removing Residents" (Grant No. 16JK2063). It is also the result of Research Project of Statistical Science of Shaanxi in 2017 (Grant No. LZ201712).

\section{References}

[1] Iacoviello, Raoul. The credit channel of monetary policy [J]. Journal of Macroeconomics, 2008, 30(1): 69-96.

[2] Li, W., R.Yao. The life-cycle effects of house price changes [J]. Journal of Money, Credit, and Banking, 2007, 39 (6): 1375-1409.

[3] Fan Chao, Wang Xueqi. Research on the Housing Price to Permanent Income Ratio of 35 Middle and Large Cities in China [J]. Statistical Research, 2016, 33(8): 95-100.

[4] Chen Wei. An Empirical Analysis of the Wealth Effect in China's Real Estate and Stock Markets, 1994-2013 [J]. Journal of Capital Normal University (Social Sciences Edition), 2015(2): 69-79. 